\title{
Evaluasi Kinerja Tata Kelola Teknologi Informasi pada Sistem Aplikasi Elektronik Program Keluarga Harapan dengan COBIT 5
}

\section{Evaluation of Information Technology Governance Performance in Electronic Application Systems of the Family Hope Program with COBIT 5}

\author{
Mailia Putri Utami ${ }^{\mathrm{a}, 1}$, Aris Puji Widodo ${ }^{\mathrm{b}, 2}$, Kusworo Adi ${ }^{\text {b }}$ \\ aUniversitas Diponegoro, Jl. Imam Bardjo SH No.5, Semarang, Indonesia \\ bUniversitas Diponegoro, Jl. Prof. Soedarto No.50275, Tembalang Semarang, Indonesia \\ email: 1mailiap@students.undip.ac.id, 2arispw@lecturer.undip.ac.id \\ Menerima: 24 November 2020, Revisi: 15 Januari 2021, Diterima: 30 Agustus 2021
}

\begin{abstract}
ABSTRAK
Penelitian ini melakukan evaluasi dan identifikasi terkait proses dari kinerja tata kelola Teknologi Informasi (TI) terhadap aplikasi Elektronik Program Keluarga Harapan (E-PKH) dengan COBIT 5 yang pada implementasinya masih banyak kekurangan yang berimbas pada kurang maksimalnya kinerja Sumber Daya Manusia (SDM) PKH dalam pelaksanaan program keluarga harapan Kementerian Sosial di Kota Semarang. Data diperoleh dari hasil kuesioner, di mana topik pembahasan mengarah pada penggunaan dari proses domain COBIT 5 yaitu Deliver, Service and Support (DSS) serta domain Monitor, Evaluate, and Assess (MAE). Hasil evaluasi dari kinerja aplikasi E-PKH dengan COBIT 5 untuk 30 responden menunjukkan pada domain DSS01 (Manage Operation) level kapabilitas mencapai rata-rata nilai 0,79, yang berarti semua kegiatan operasional berdasasarkan standar COBIT 5 sudah terlaksana, di samping itu masih ada beberapa catatan yang perlu ditingkatkan, baik dari infrastruktur Teknologi Informasi yang sudah ada atau dengan dilakukannya kerjasama dengan pihak ketiga yang sudah berpengalaman untuk meningkatkan standar kualitas dari infrastruktur Teknologi Informasi. Domain DSS04 (Manage continuity) level kapabilitas dengan nilai 0,98 dari nilai ini Direktorat Jaminan Sosial yang menaungi Program Keluarga Harapan memerlukan sebuah manajemen untuk penanganan kemampuan atau skills dari SDM Program Keluarga Harapan dalam menjalankan bisnis proses yang lebih baik dari sistem yang ada.

Kata kunci : COBIT 5, DSS, MAE, Sistem E-PKH.
\end{abstract}

\section{ABSTRACT}

In this research, evaluation and identification have been carried out related to the process of the performance of Information Technology (IT) governance on the Electronic Family Hope Program (E-PKH) application with COBIT 5, which in its implementation there are still many shortcomings which impact the performance of Human Resources (HR). PKH in the implementation of the Ministry of Social's expected family program in Semarang City. Data obtained from the results of a questionnaire, where the topic of discussion leads to the use of the COBIT 5 domain process, namely Deliver, Service and Support (DSS) and the Domain Monitor, Evaluate, and Assess (MAE). The results of the evaluation of the performance of the E-PKH application with COBIT 5 for 30 correspondents show that in the DSSO1 (Manage Operation) domain the capability level reaches an average value of 0.79 , which means that all operational activities based on the COBIT 5 standard have been carried out, but there are still some notes that need to be improved again from the Information Technology infrastructure that is currently owned or by collaborating with experienced third parties to improve the quality standards of Information Technology infrastructure, especially in the management of the E-PKH application infrastructure which there are still many obstacles to the usefulness of the application. Domain DS04 (Manage continuity) capability level with a value of 0.98 of this value. The Directorate of Social Security which oversees the Family Hope Program requires a management to handle the abilities or skills of the Harapan Family Program HR in running a better business process.

Keyword : COBIT 5, DSS, E-PKH System, MAE. 


\section{PENDAHULUAN}

Perkembangan dan kemajuan teknologi, tata kelola Sistem Informasi (SI) atau Teknologi Informasi (TI) yang sesuai, sangat mendukung segala aktivitas suatu organisasi dalam mencapai suatu target ataupun sasaran dalam organisasi (visi dan misi). Tata kelola SI/TI sekarang ini sangat berpengaruh terhadap kinerja bisnis dalam memilih, mengevalusi berbagai aspek penunjang di dalam suatu bisnis. Adanya tata kelola diharapkan organisasi mampu menggali potensi, serta mengevalusi segala kekurangan dan mampu memberikan manfaat ekonomis dalam proses bisnis (Wulandari dkk., 2019). Evaluasi dan audit TI bertujuan untuk mengevaluasi dan memastikan bahwa proses TI yang telah dilakukan dalam organisasi berdasarkan prosedur operasi standar yang diterapkan yang digunakan untuk memelihara dan memantau proses tersebut (Sarno., 2009).

Tata kelola sangat membantu untuk memandu dan mengendalikan suatu organisasi dalam mencapai tujuan yang telah direncanakan sebelumnya. Adanya tata kelola teknologi informasi kemungkinan akan mendukung suatu organisasi untuk menjalankan TI-nya agar lebih terarah dan mampu mengkoordinasikan antara proses dan manfaat yang ada (Fauzan \& Latifah, 2015). Pentingnya TI juga menjadi prioritas di sektor publik yang melayani masyarakat untuk memberikan strategi layanan yang tepat sasaran dan optimal. Standar tata kelola TI yang baik dapat memberikan transparasi dan pengambilan keputusan yang jelas serta wewenang dan tanggung jawab yang terstruktur. Pemerintahan yang baik adalah yang mementingkan aset publik mencakup tata kelola yang baik pada TI (Juiz dkk., 2014).

Program Keluarga Harapan (PKH) adalah program pemberian bantuan sosial bersyarat kepada keluarga atau seseorang miskin dan rentan yang terdaftar dalam data terpadu program penanganan fakir miskin, diolah oleh Pusat Data dan Informasi Kesejahteraan Sosial dan ditetapkan sebagai Keluarga Penerima Manfaat (KPM). PKH memiliki tujuan untuk meningkatkan taraf hidup dan mengurangi beban pengeluaran dan meningkatkan pendapatan keluarga miskin dan rentan. Sebagai sebuah program bantuan sosial bersyarat, dengan mempertahankan taraf kesejahteraan sosialnya sesuai dengan amanat konstitusi dan Nawacita Presiden RI (Peraturan Menteri Sosial Nomor 12018 Tentang Program Keluarga Harapan, 2018).

Penelitian ini memerlukan suatu kerangka kerja sebagai reference model, untuk memastikan kualitas tata kelola TI pada evaluasi performa sistem E-PKH. Kekurangan yang dirasakan pada sistem E-PKH baik dari segi User Interface (UI), aplikasi kurang user friendly jika diakses melalui smartphone, dan juga dari performa yang sering mengalami down ketika mendekati deadline, perlunya evaluasi serta penilaian performa sistem E-PKH, agar semua pengguna tidak lagi mengalami kesulitan dan dapat merasakan manfaat dari adanya sistem tersebut. Dengan adanya referensi model, maka tujuan, aplikabilitas, terminologi, pesan dan tanggung jawab, serta kerangka konseptual dan maturitas tata kekola sistem E-PKH dapat diidentifikasi. Reference model yang digunakan yaitu COBIT (Control Objective for Information and Rekated Technology) versi 5, yang mana merupakan sebuah kerangka kerja berupa produk panduan best practies yang menyajikan kegiatan dalam struktur organisasi TI yang dikelola dan logis, disusun oleh para ahli di bidang tata kelola TI, dan lebih berfokus pada kontrol evaluasi performa (Wulandari dkk., 2019). Framework COBIT 5 dengan domain DSS dan MAE dalam mengevaluasi kinerja tata kelola pada implementasi Sistem E-PKH, diharapkan mampu meningkatkan pengukuran kinerja SI/TI pada Program Keluarga Harapan Kementerian Sosial.

\section{Studi Literatur}

Pengertian tata kelola TI adalah tentang memastikan pengelolaan teknologi informasi untuk mendukung bahkan selaras dengan strategi bisnis suatu perusahaan yang dilakukan oleh direksi, manajemen pelaksana, dan juga oleh manajemen teknologi informasi (Durachman dkk., 2017). Saat ini, teknologi informasi dianggap sebagai aset penting dan langkah awal strategis bagi suatu organisasi publik atau swasta maupun korporasi, semakin meningkat organisasi tersebut bisa dikarenakan karena pengaruh penting dari TI. TI memainkan peran yang fundamental dan mentrasformasikan setiap elemen organiasasi publik, tidak lagi hanya menjadi sebatas objek dari manajemen, tetapi perannya yang menjadi tata kelola sebuah isi dari organisasi (Santos \& Santos, 2017).

Huang (2009) menyatakan bahwa organisasi yang menggunakan TI perlu melakukan Tata Kelola TI agar dapat memperoleh manfaat yang maksimal (Huang dkk., 2009). Peran serta tanggung jawab masing-masing anggota organisasi menjadi hak dan beban yang harus dikerjakan, agar setiap keputusan yang dibuat berdasarkan hasil dari tata kelola TI menjadi bermanfaat dan memiliki nilai tambah untuk organisasi tersebut. Keputusan tersebut merupakan salah satu, peran penting setelah dilakukannya monitoring, dan review dari setiap elemen pekerjaan yang telah dikerjakan, di mana diharapkan dapat membentuk organisasi dan tata kelola TI yang lebih baik lagi, sehingga terus bisa mengembangkan inovasi dalam organisasi. Hal ini juga didorong oleh penelitian Woong Chul Choi dan Dae Houn Yoo (2009), penelitian mereka adalah menetapkan penilaian tata kelola TI menggunakan kerangka kerja COBIT untuk memprioritaskan investasi TI di organisasi (Choi \& Yoo, 2009).

COBIT (Control Objective for Information and Rekated Technology) adalah sekumpulan dokumentasi dan pedoman untuk penerapan tata kelola TI, sebuah kerangka kerja yang membantu auditor, manajemen, dan pengguna untuk menjembatani pemisahan ( $g a p$ ) antara risiko bisnis, pengendalian kebutuhan, dan masalah 
teknis. COBIT telah mengalami evaluasi yang cukup lama menjadi lebih baik menjadi kerangka kerja yang dapat digunakan dalam mengimplementasikan Tata Kelola TI perusahaan (Harefa \& Legowo, 2017).

Pada COBIT 5 adanya model kapabilitas proses, yang berdasarkan pada ISO/IEC 15504, standar mengenai Software Engineering dan Process Assessment. Model ini mengukur performa tiap-tiap proses tata kelola (EDMbased) atau proses manajemen (PBRM-based) untuk mengidentifikasi area yang akan ditingkatkan performanya (Hakim dkk., 2014).

COBIT 5 merupakan framework yang akan digunakan pada penelitian ini. COBIT 5 adalah kerangka kerja untuk tata kelola dan manajemen manajemen TI. COBIT 5 memungkinkan TI terkait terorganisir dan dikelola secara keseluruhan untuk organisasi yang terkait dengan proses bisnis end-to-end sepenuhnya dan tanggung jawab fungsional era. serta mempertimbangkan TI sesuai dengan kepentingan pemangku kepentingan internal dan eksternal (Harefa \& Legowo, 2017). Pengertian lain terkait COBIT 5 yaitu salah satu kerangka kerja berupa produk panduan best practices yang menyajikan kegiatan dalam struktur organisasi TI yang dikelola dan logis, disusun oleh para ahli di bidang tata kelola TI, dan lebih berfokus pada control evaluasi performa (Wulandari dkk., 2019).

COBIT telah mengalami evaluasi yang cukup lama menjadi lebih baik menjadi kerangka kerja yang dapat digunakan dalam melaksanakan Tata Kelola Perusahaan. Menurut (ISACA, 2012), COBIT 5 merupakan pedoman ISACA generasi terbaru yang membahas tentang tata kelola dan manajemen TI. COBIT 5 dibuat berdasarkan pengalaman penggunaan COBIT selama lebih dari 15 tahun oleh banyak perusahaan dan pengguna dari bidang bisnis, komunitas IT, risiko, asuransi, dan keamanan. Berikut merupakan gambaran evolusi COBIT, pada Gambar 1 (Durachman dkk., 2017).

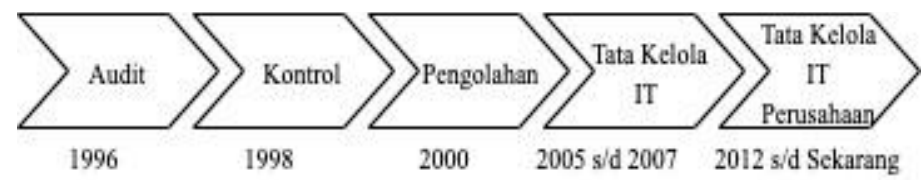

Gambar 1. Evolusi Perkembangan COBIT

COBIT 5 didasarkan pada lima prinsip utama tata kelola dan manajemen organisasi TI seperti pada Gambar 2 (AB dkk., 2017).

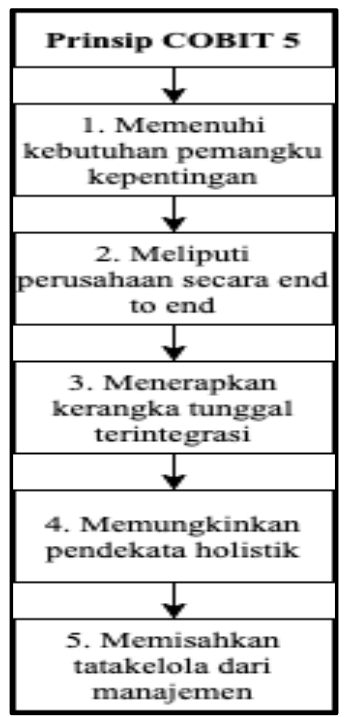

Gambar 2. Prinsip Utama COBIT 5

\section{METODE PENELITIAN}

Gambar 3 Diagram alur adalah proses dari alur kerja, di mana untuk setiap langkah yang digunakan dalam proses mengevaluasi kinerja dari tata kelola teknologi informasi terhadap aplikasi E-PKH Kota Semarang. 


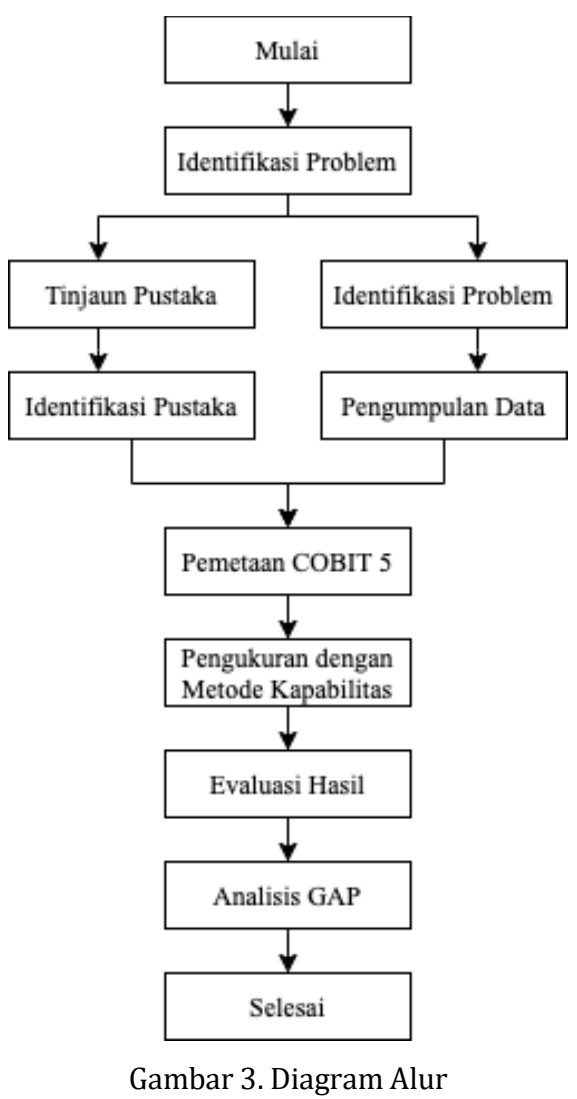

Proses pengumpulan data yaitu dengan membagikan kuesioner terhadap pengguna dari Aplikasi E-PKH dan staf pekerja. Setiap pertanyaan pada kusioner terkait domain yang digunakan, laporan hasil kuesioner disebarkan (dengan jumlah 110 kuesioner), dimana data yang terkumpul diolah untuk dihitung berdasarkan perhitungan tingkat Process Capability Model. Hasil audit berisi temuan masa kini (tingkat model kemampuan proses saat ini) dan harapan di masa mendatang (tingkat model kemampuan proses yang diharapkan). Langkah selanjutnya adalah menghitung gap analysis untuk menganalisis interpretasi level Process Capability Model saat ini dan yang diharapkan dan memberikan daftar rekomendasi tindakan korektif untuk mengatasi gap, untuk mencapai perbaikan tata kelola TI (Andry, 2016). adapaun domain yang digunakan pada penelitian ini adalah:

1) Domain (Deliver, Service and Support) DSS01, yang mencakup catatan mengenai manage operations, poin-poin dari domain DSS01 pada pertanyaan tersebut menyangkut : Layanan IT sesuai dengan kebutuhan bisnis dan optimalisasi aset, sumber daya dan kapabilitas TI. (Saridewi dkk., 2018).

2) Domain (Deliver, Service and Support) DSS03, yang mencakup tinjauan mengenai manage problems, mengindentifikasi akar dari permasalahan yang ada dengan tujuan yaitu untuk memperbaiki dan memberikan rekomendasi solusi yang lebih baik (Wella, 2016).

3) Domain (Deliver, Service and Support) DSS04, yang mencakup tinjauan mengenai manage continuity. Pengukuran manajemen keberlangsungan bisnis proses. Poin-poin dari domain DSS04 pada pertanyaan tersebut menyakut layanan informasi dan kebijakan untuk pengambilan keputusan

4) Domain (Deliver, Service and Support) DSS06, yang mencakup tinjaun mengenai manage business process controls. Pemeliharaan dan mendefinisakan kontrol dari proses bisnis yang tepat sesuai dengan informasi terkait (Wella, 2016).

5) Domain (Monitor, Evaluate, and Assess) MEA01. Fokus utama yaitu terkait proses pengawasan bagaimana TI dijalankan sesuai dengan SOP perusahaan, serta memonitoring efektivitas dari sistem aplikasi E-PKH. Poinpoin dari domain MAE01 pada pertanyaan tersebut menyangkut Kebijijakan, rencana dan prosedur, Alat dan otomasi, Kemampuan dan keahlian, Tanggung jawab dan akuntabilitas, Penetapan dan pengukuran tujuan. (Purbawangsa dkk., 2014).

6) Domain (Monitor, Evaluate, and Assess) MEA02. Fokus utama yaitu terkait proses pengawasan dan evaluasi TI aplikasi, serta memonitoring efektivitas dari sistem aplikasi secara berkala.

Menurut acuan terhadap tingkat kapabilitas, terdapat enam tingkatan, di antaranya (ISACA, 2012):

Tabel 1. Interval Grade of Governance Capability TI

\begin{tabular}{ccc}
\hline Indeks Kapabilitas & Level Kapabilitas & Status \\
\hline $0-0,49$ & 0 & Incomplate \\
\hline $0,50-1,49$ & 1 & Performed \\
\hline
\end{tabular}




\begin{tabular}{ccc}
\hline Indeks Kapabilitas & Level Kapabilitas & Status \\
\hline $1,50-2,49$ & 2 & Managed \\
\hline $2,50-3,49$ & 3 & Established \\
\hline $3,50-4,49$ & 4 & Predictable \\
\hline $4.50-5,00$ & 5 & Optimizing \\
\hline
\end{tabular}

\section{HASIL DAN PEMBAHASAN}

\section{Hasil Analisis Domain DSS (Deliver, Service and Support)}

Pada domain DSS01 dengan tujuan manage operations, lebih menekankan untuk pegukuran kinerja operasional dalam pengelolaan Teknologi Informasi secara rutin. Tujuan sub domain ini adalah untuk menilai koordinasi dan pelaksanaan kegiatan termasuk prosedur operasional yang penting dan diperlukan untuk penyampaian layanan TI internal dan outsourcing yang optimal. Subdomain ini juga mencakup pelaksanaan prosedur operasi standar yang telah ditetapkan sebelumnya dan aktivitas pemantauan yang diperlukan (Andry \& Setiawan, 2019). Domain ini terdiri enam pernyataan, berikut dengan hasil nilai dapat dilihat pada Tabel 2.

Tabel 2. Current Capability Sub Domain DSS01

\begin{tabular}{lc}
\hline \multicolumn{1}{c}{ Proses } & Current Capability Level \\
\hline $\begin{array}{l}\text { (DSS01.01) } \\
\text { Melakukan prosedur operasional }\end{array}$ & \\
\hline $\begin{array}{l}\text { (DSS01.02) } \\
\text { Mengelola layanan TI yang dialihdayakan }\end{array}$ & 0,85 \\
\hline $\begin{array}{l}\text { (DSS01.03) } \\
\text { Memantau infrastruktur TI }\end{array}$ & 0,58 \\
\hline $\begin{array}{l}\text { (DSS01.04) } \\
\text { Mengelola lingkungan }\end{array}$ & 0,81 \\
\hline $\begin{array}{l}\text { MSS01.05) } \\
\text { Tengelola fasilitas }\end{array}$ & 0,93 \\
\hline & $\mathbf{0 , 7 9}$
\end{tabular}

Domain DSS03 dengan tujuan manage problems, lebih menekankan untuk pengukuran manajemen penanganan masalah pada layanan Teknologi Informasi Aplikasi E-PKH di Program Keluarga Harapan. Domain ini terdiri tiga pernyataan dengan hasil nilai dapat dilihat pada Tabel 3.

Tabel 3. Current Capability Sub Domain DSS03

\begin{tabular}{lc}
\hline \multicolumn{1}{c}{ Proses } & Current Capability Level \\
\hline $\begin{array}{l}\text { (DSS03.01) } \\
\text { Mengidentifikasi dan mengklasifikasi masalah }\end{array}$ & 1,17 \\
\hline $\begin{array}{l}\text { (DSS03.02) } \\
\text { Menyelidiki dan mendiagnosis masalah }\end{array}$ & 1,37 \\
\hline (DSS03.03) & 1,23 \\
\hline Meningkatkan kesalahan yang diketahui & \\
Mengatasi dan menutup masalah & \\
\hline (DSS03.05) & \\
Lakukan manajemen masalah secara proaktif. & 1,26 \\
\hline
\end{tabular}

TOTAL RATA-RATA

Domain DSS04 dengan tujuan Manage Continuity, lebih menekankan untuk pengukuran manajemen keberlangsungan bisnis proses pada Teknologi Informasi Aplikasi E-PKH di Program Keluarga Harapan. Domain ini terdiri lima pernyataan dengan hasil nilai dapat dilihat pada Tabel 4.

Tabel 4. Current Capability Sub Domain DSS04

\section{Proses}

Current Capability Level

(DSS04.01)

Mendefinisikan kebijakan, tujuan dan ruang lingkup bisnis yang berkelanjutan

(DSS04.02)

Menjaga strategi kontinuitas

(DSS04.03)

Mengembangkan dan menerapkan respons kelangsungan bisnis.

(DSS04.04)

Latihan, uji dan kaji ulang BCP.

28 | Volume 10 Nomor 1 /Juni 2021 http://doi.org/10.31504/komunika.v9i1.3529

(c) 2021 Jurnal Komunika:Jurnal Komunikasi dan Informatika. Semua hak cipta dilindungi undang-undang. 
(DSS04.05)

Meninjau, memelihara dan meningkatkan rencana kesinambungan.

1

(DSS04.06)

Melakukan pelatihan rencana kesinambungan

0,88

\section{TOTAL RATA-RATA}

0,98

Pada domain DSS06 dengan tujuan Manage Business Process Controls, lebih menekankan untuk pengukuran manajemen pengendalian bisnis proses bejalan baik pada Teknologi Informasi Aplikasi E-PKH di Program Keluarga Harapan. Domain ini terdiri enam pernyataan dengan hasil nilai dapat dilihat pada Tabel 5.

Tabel 5. Current Capability Sub Domain DSS06

\begin{tabular}{lc}
\multicolumn{1}{c}{ Proses } & $\begin{array}{c}\text { Current Capability } \\
\text { Level }\end{array}$ \\
\hline $\begin{array}{l}\text { (DSS06.01) } \\
\text { Menyelaraskan aktivitas pengendalian yang tertanam dalam proses bisnis dengan tujuan } \\
\text { perusahaan }\end{array}$ & 0,96 \\
\hline $\begin{array}{l}\text { (DSS06.02) } \\
\text { Mengontrol pemrosesan informasi. }\end{array}$ & 1,00 \\
\hline $\begin{array}{l}\text { (DSS06.03) } \\
\text { Mengelola peran, tanggung jawab, hak akses dan tingkat otoritas. }\end{array}$ & 0,96 \\
\hline $\begin{array}{l}\text { (DSS06.04) } \\
\text { Mengelola kesalahan dan pengecualian }\end{array}$ & 0,98 \\
\hline $\begin{array}{l}\text { (DSS06.05) } \\
\text { Memastikan keterlacakan peristiwa informasi dan akuntabilitas }\end{array}$ & \\
\hline $\begin{array}{l}\text { (DSS06.06) } \\
\text { Tengamankan aset informasi. }\end{array}$ & $\mathbf{0 , 9 7}$ \\
\hline
\end{tabular}

\section{Hasil Analisis Domain MEA (Monitor, Evaluate, and Assess)}

Pada domain MEA01 dengan tujuan monitor, evaluate and assess performance and conformance, lebih menekankan untuk pengukuran mengumpulkan, memvalidasi, dan mengevaluasi bisnis proses, Teknologi Informasi pada aplikasi E-PKH di Program Keluarga Harapan. Domain ini terdiri dua pernyataan dengan hasil nilai dapat dilihat pada Tabel 6.

Tabel 6. Current Capability Sub Domain MEA01

\section{Proses}

\section{(MEA01.01)}

Memantau, mengevaluasi dan menilai kinerja dan kesesuaian.

(MEA01.02)

Tetapkan target kinerja dan kesesuaian.

(MEA01.03)

Mengumpulkan dan memproses data kinerja dan kesesuaian

(MEA01.04)

Menganalisis dan melaporkan kinerja

(MEA01.05)

Memastikan penerapan tindakan korektif.

TOTAL RATA-RATA

\section{Current Capability Level}

1,85

1,85

Pada domain MEA02 dengan tujuan monitor, evaluate and assess the System of Internal Control, lebih menekankan untuk pengukuran dalam memantau, mengevaluasi kekurangan dan perencanaan untuk menerapkan hasil evaluasi pada Aplikasi E-PKH di Program Keluarga Harapan. Domain ini terdiri dua pernyataan dengan hasil nilai dapat dilihat pada Tabel 7.

Tabel 7. Current Capability Sub Domain MEA02

Proses

\section{Current Capability Level}

(MEA02.01)

Memantau pengendalian internal

(MEA02.02)

Meninjau efektivitas pengendalian proses bisnis.
1,93

1,85

29 | Volume 10 Nomor 1 /Juni 2021 http://doi.org/10.31504/komunika.v9i1.3529

(C) 2021 Jurnal Komunika:Jurnal Komunikasi dan Informatika. Semua hak cipta dilindungi undang-undang. 
(MEA02.03)

Lakukan penilaian diri kontrol

(MEA02.04)

Identifikasi dan laporkan kekurangan pengendalian.

(MEA02.05)

Pastikan bahwa penyedia jaminan independen dan berkualitas.

(MEA02.06)

Merencanakan inisiatif jaminan

(MEA02.07)

Prakarsa jaminan ruang lingkup

(MEA02.08)

Jalankan inisiatif jaminan

\section{TOTAL RATA-RATA}

\section{Analisis Kesenjangan Kapabilitas (GAP)}

Berdasarkan hasil dan Analisa terhadap kesenjangan antara Expected Capability dan Current Capability di atas maka akan diberikan rekomendasi untuk proses perbaikan sehingga pada level capability tata kelola Teknologi Informasi Program Keluarga Harapa yang bertujuan untuk mencapai hasil yang diinginkan dan sesuai yang diharapkan. Proses yang akan diberikan rekomendasi adalah yang memiliki level kapabilitas < 1 , rekomendasi perbaikan ini bersumber dari analisis hasil perhitungan dan analisis level ability gap sebagai bentuk desain solusi untuk memberikan usulan yang disusun secara langsung sehingga perusahaan dapat meningkatkan tingkat kematangannya sesuai dengan yang diharapkan. Penentuan rekomendasi dilakukan dengan memberikan solusi perbaikan untuk setiap proses yang belum maksimal hingga 100\% (Putri dkk., 2017). Proses tersebut dapat dilihat pada Tabel 8.

Tabel 8. Proses Yang Perlu Dilakukan Perbaikan.

\begin{tabular}{|c|c|c|c|}
\hline Proses TI & $\begin{array}{l}\text { Current } \\
\text { Capability }\end{array}$ & $\begin{array}{c}\text { Expect } \\
\text { Capability }\end{array}$ & GAP \\
\hline $\begin{array}{l}\text { (DSS01.03) } \\
\text { Memantau infrastruktur TI }\end{array}$ & 0,58 & 1 & 0,42 \\
\hline $\begin{array}{l}\text { (DSS01.04) } \\
\text { Mengelola lingkungan }\end{array}$ & 0,81 & 1 & 0,19 \\
\hline (DSS01.02) Mengelola layanan Teknologi Informasi yang dialihdayakan & 0,85 & 1 & 0,15 \\
\hline $\begin{array}{l}\text { (DSS04.06) } \\
\text { Melakukan pelatihan rencana kesinambungan }\end{array}$ & 0,88 & 1 & 0,12 \\
\hline
\end{tabular}

Rekomendasi adalah bentuk saran dari auditor yang sifatnya menganjurkan untuk membantu menyelesaikan masalah yang ada. Rekomendasi didapat dari hasil kapabilitas level proses TI saat ini dan kapabilitas yang diinginkan. Rekomendasi yang diberikan diharapkan mampu membantu memberikan solusi yang tepat terhadap manajemen kualitas yang dimiliki perusahaan. Rekomendasi akan disusun berdasarkan kondisi sesungguhnya yang terjadi di perusahaan (Kuntadihardja \& Tanaamah, 2019). Rekomendasi Evaluasi Pengelolaan Operasional (DSS01) dengan hasil level kapabilitas 0.98 , maka berikut poin yang perlu ditingkatkan atau diperbaiki sebagai tahap evaluasi:

1. Menghapus fasilitas koneksi internet Sistem Informasi Kesejahteraan Sosial (SIKS) yang terdapat disetiap sekretariat, ini dikarenakan sistem informasi E-PKH dapat diakses menggunakan koneksi internet biasa dan jika dipakai jaringan sendiri sering mengalami lost. Kondisi berbeda ketika masih menggunakan sistem informasi terdahulu yang harus menggunakan intranet untuk dapat mengaksesnya, dimungkin bisa untuk meningkatkan (DSS01.02).

2. Jika tetap dikehendaki menyediakan koneksi internet SIKS disetiap sekretariat, sebaiknya meningkatkan kecepatan jaringan untuk akses, dengan menggandeng pihak ketiga yaitu Internet Service Provider (ISP) yang memiliki layanan mumpuni (DSS01.02).

3. Meningkatkan kapasitas server yang dimiliki Kementerian Sosial dan bandwidth untuk mengakses Sistem Informasi E-PKH bisa diperbesar sehingga lebih cepat dan maksimal dalam mengakses terutama ketika pemutakhiran global (DSS01.03).

4. Menyediakan tempat yang layak seperti pendingin dan alat pemadam kebakaran untuk melindungi perangkat jaringan untuk koneksi SIKS yang terdapat di setiap sekretariat (DSS01.04).

5. Merencanakan audit secara independen dengan melibatkan pihak ketiga seperti Kementerian Kominfo atau penyedia layanan software enginer yang sudah berpengalaman sehingga bias mendapatkan masukkan atau bahkan melakukan kerjasama untuk meningkatkan kualitas dari sistem informasi E-PKH (DSS01.05). 


\section{KESIMPULAN}

Berdasarkan dari hasil proses audit tata kelola teknologi informasi dapat disimpukan bahwa, dari hasil rekapitulasi level kapabilitas audit tata kelola teknologi informasi di Program Keluarga Harapan dapat ditarik kesimpulan sebagai berikut :

1. Pada domain DSS01 (Manage Operation) level kapabilitas mencapai rata-rata nilai 0,79, dari nilai ini berarti semua kegiatan operasional berdasarkan standar COBIT 5 sudah terlaksana. Akan tetapi masih ada beberapa catatan yang perlu ditingkatkan lagi dari infrastruktur TI yang sudah dimiliki saat ini atau melakukan kerjasama dengan pihak ketiga yang sudah berpengalaman untuk meningkatkan standar kualitas dari infrastruktur TI sehingga pelaksanaan bisnis proses bisa lebih optimal.

2. Pada domain DS04 (Manage continuity) level kapabilitas dengan nilai 0,98 dari nilai ini Direktorat Jaminan Sosial yang menaungi Program Keluarga Harapan memerlukan sebuah manajemen untuk penanganan kemampuan atau skills dari SDM Program Keluarga Harapan dalam menjalankan bisnis proses. Direktorat Jaminan Sosial dapat melakukan pemantauan dengan mengadakan pelatihan secara berkala dan melakukan tes untuk megukur sejauh mana kualitas dari SDM.

\section{DAFTAR PUSTAKA}

AB, M., Prihandoko, -, E, P., \& C, W. (2017). Analyzing COBIT 5 IT Audit Framework Implementation using AHP Methodology. JOIV: International Journal on Informatics Visualization, 1(2), 33. https://doi.org/10.30630/joiv.1.2.18

Andry, J. F. (2016). Performance Measurement of Information Technology Governance: A Case Study. Jurnal Sistem Informasi (Journal of Information, 12, 90-94. https://cloud.politala.ac.id/politala/1. Jurusan/Teknik Informatika/19. e-journal/Jurnal Nasional TI/Jurnal Sistem Informasi (Journal of information systems)/Volume 12/Nomor 1/452-Article Text-1313-3-10-20170831_VISUALIZATION OF ONTOLOGYBASED DATA WAREHO

Andry, J. F., \& Setiawan, A. K. (2019). It Governance Evaluation Using Cobit 5 Framework on the National Library. Jurnal Sistem Informasi, 15(1), 10-17. https://doi.org/10.21609/jsi.v15i1.790

Choi, W., \& Yoo, D. (2009). Assessment of IT governance of COBIT framework. Communications in Computer and Information Science, 62, 82-89. https://doi.org/10.1007/978-3-642-10580-7_13

Durachman, Y., Chairunnisa, Y., Soetarno, D., Setiawan, A., \& Mintarsih, F. (2017). IT security governance evaluation with use of COBIT 5 framework: A case study on UIN Syarif Hidayatullah library information system. 2017 5th International Conference on Cyber and IT Service Management, CITSM 2017. https://doi.org/10.1109/CITSM.2017.8089302

Fauzan, R., \& Latifah, R. (2015). Audit Tata Kelola Teknologi Informasi Untuk Mengontrol Manajemen Kualitas Menggunakan Cobit 4.1 (Studi Kasus : PT Nikkatsu Electric Works). Jurnal Teknik Informatika Dan Sistem Informasi, 1(3), 235-244. https://doi.org/10.28932/jutisi.v1i3.402

Hakim, A., Saragih, H., \& Suharto, A. (2014). Evaluasi Tata Kelola Teknologi Informasi Dengan Framework COBIT 5 Di Kementrian ESDM (Studi Kasus pada Pusat Data dan Teknologi Informasi ESDM). Jurnal Sistem Informasi, 10(2), 83-86.

Harefa, K. R. P., \& Legowo, N. (2017). The governance measurement of information system using framework cobit 5 in automotive company. Proceedings - 2017 International Conference on Applied Computer and Communication Technologies, ComCom 2017, 2017-Janua, 1-6. https://doi.org/10.1109/COMCOM.2017.8167104

Huang, Z., Zavarsky, P., \& Ruhl, R. (2009). An efficient framework for IT controls of bill 198 (Canada SarbanesOxley) compliance by aligning COBIT 4.1, ITIL v3 and ISO/IEC 27002. Proceedings - 12th IEEE International Conference on Computational Science and Engineering, CSE 2009, 3, 386-391. https://doi.org/10.1109/CSE.2009.336

ISACA. (2012). Enabling Processes. In Cobit 5.

Juiz, C., Guerrero, C., \& Lera, I. (2014). Implementing Good Governance Principles for the Public Sector in Information Technology Governance Frameworks. Open Journal of Accounting, 03(01), 9-27. https://doi.org/10.4236/ojacct.2014.31003

Peraturan Menteri Sosial Nomor 12018 Tentang Program Keluarga Harapan, Pub. L. No. 1 (2018).

Kuntadihardja, C. H., \& Tanaamah, A. R. (2019). Analisis Audit Sistem Informasi Berbasis COBIT 5 Pada Subdomain AP011 Manage Quality. Jurnal SITECH: Sistem Informasi Dan Teknologi, 2(1), $109-120$. https://doi.org/10.24176/sitech.v2i1.3492

Purbawangsa, I. N., EkoDarwiyanto, ST., M., \& KemasRahmat S.W., ST., M. E. (2014). EvaluasiSistem E-Government 
Kota Denpasar Menggunakan Framework COBIT 5 pada Domain Monitor, Evaluate and Assess (MEA). 1(1), $1-10$.

Putri, M. A., Aknuranda, I., \& Mahmudy, W. F. (2017). Maturity Evaluation of Information Technology Governance in PT DEF Using Cobit 5 Framework. Journal of Information Technology and Computer Science, 2(1), 19-27. https://doi.org/10.25126/jitecs.20172123

Santos, L. C., \& Santos, C. D. dos. (2017). A study on the impact of non-operational mechanisms on the effectiveness of public information technology governance. Revista de Administração, 52(3), $256-267$. https://doi.org/10.1016/j.rausp.2017.05.005

Saridewi, A. I., Wiharta, D. M., \& Sastra, N. P. (2018). Evaluation of Integrated University Management Information System Using COBIT 5 Domain DSS. 2018 International Conference on Smart Green Technology in Electrical and Information Systems: Smart Green Technology for Sustainable Living, ICSGTEIS 2018 Proceeding, 7, 210-214. https://doi.org/10.1109/ICSGTEIS.2018.8709144

Sarno, R (2009). Audit System and Information Technology. In Audit System and Technology Information. Insitute Technology of Surabaya Publisher. Surabaya, Indonesia.

Wella. (2016). Audit Sistem Informasi Menggunakan Cobit 5 . 0 Domain DSS pada. ULTIMS InfoSys, VII(1), 38-44.

Wulandari, S. A., Dewi, A. P., Rizki Pohan, M., Sensuse, D. I., Mishbah, M., \& Syamsudin. (2019). Risk assessment and recommendation strategy based on COBIT 5 for risk: Case study sikn Jikn helpdesk service. Procedia Computer Science, 161, 168-177. https://doi.org/10.1016/j.procs.2019.11.112 